\title{
Género y poshumanismo en la novela gráfica chilena y argentina
}

\author{
Joanna Page \\ Universidad de Cambridge \\ jep29@cam.ac.uk
}

Si en muchos casos los medios nos ofrecen representaciones de género cada vez más heterogéneas, es notable que las historietas, en su mayoría, siguen recurriendo a los clichés de mujeres voluptuosas medio desnudas y superhéroes exageradamente musculosos. La tendencia de crear imágenes al borde de la pornografía muchas veces se explica sosteniendo que los lectores de historietas han sido mayormente adolescentes masculinos. Sin embargo, es evidente que la ola reciente de novelas gráficas en Europa, Norteamérica y América Latina se dirigen a un público adulto más amplio. A su vez, la explicación es insuficiente porque no logra captar porqué estos textos producen representaciones hiperbólicas del género y de la sexualidad que enfatizan los aspectos biológicos del género, y que corren el riesgo de parecer anticuadas o retrógradas en una época en que el género comienza a entenderse más como una construcción cultural y social.

En este artículo voy a analizar el tratamiento del género y de la sexualidad en algunos ejemplos de la novela gráfica reciente en Chile y Argentina. Voy a proponer como hipótesis que la representación aparentemente estereotipada o convencional del género -y de la masculinidad en particular- juega un rol importante en el desarrollo en estos textos de una crítica de la modernidad. Esta crítica se construye a base de la importancia de la materialidad y de la corporización en un mundo poshumano. El énfasis que ponen sobre la materialidad del cuerpo también responde al llamado de R. W. Connell a reafirmar el rol protagónico de los cuerpos en los procesos sociales, en un contexto en que muchas veces se borran de la teoría social. También, como voy a plantear, provee la base de una nueva ética en el contexto poshumano.

Una mirada crítica hacia la modernidad y la dominación humanista de la naturaleza atraviesa la obra de Diego Agrimbau. Sus novelas gráficas denuncian la creencia arrogante en la inevitabilidad del progreso humano y develan el costo de una modernidad explotadora y desigual. En Planeta Extra de Diego Agrimbau y Gabriel Ippóliti, la representación de la masculinidad en el texto se encuentra en una relación de oposición con nociones del progreso capitalista. En general, los valores y las características del hombre de familia tradicional se muestran incompatibles con la modernización. El retrato algo cariñoso de cierta versión de la masculinidad se convierte en un eje central de la crítica que el texto hace de la modernidad occiden- 
tal. También traza un retorno nostálgico a lo nacional y lo popular frente al rápido cambio social y tecnológico.

En Planeta Extra, así como en muchas de las obras de Agrimbau, la modernidad tecnológica y la explotación del medio ambiente han producido una destrucción ecológica generalizada y una falta cada vez mayor de justicia social. La superpoblación, la contaminación, la corrupción y los delitos que destacan en muchos centros urbanos del Tercer Mundo se han extendido en Planeta Extra hasta cubrir el planeta entero. Habiendo saqueado todos los recursos naturales del mundo, los que tienen el dinero necesario han abandonado la Tierra para vivir en un planeta con una mejor calidad de vida, una luna que se encuentra en el lado oculto de Júpiter. El texto presenta el tema de la desigualdad de una manera lúdica, al introducir vehículos voladores, viajes espaciales y animales virtuales en una ciudad que obviamente se ha quedado atrás en la carrera tecnológica (A, B). La ciudad futurista que vemos también incluye los camiones desvencijados de mudanzas, las autopistas congestionadas y las manifestaciones omnipresentes que componen el paisaje urbano del Buenos Aires contemporáneo. Como dice Agrimbau, se trata de una "ciencia ficción de barrio" (Abella). Uno de los logros de Planeta Extra es la construcción de una ciencia ficción en clave vernácula, claramente arraigada en la imaginación popular y en las tradiciones y espacios domésticos de un típico barrio obrero de Buenos Aires.

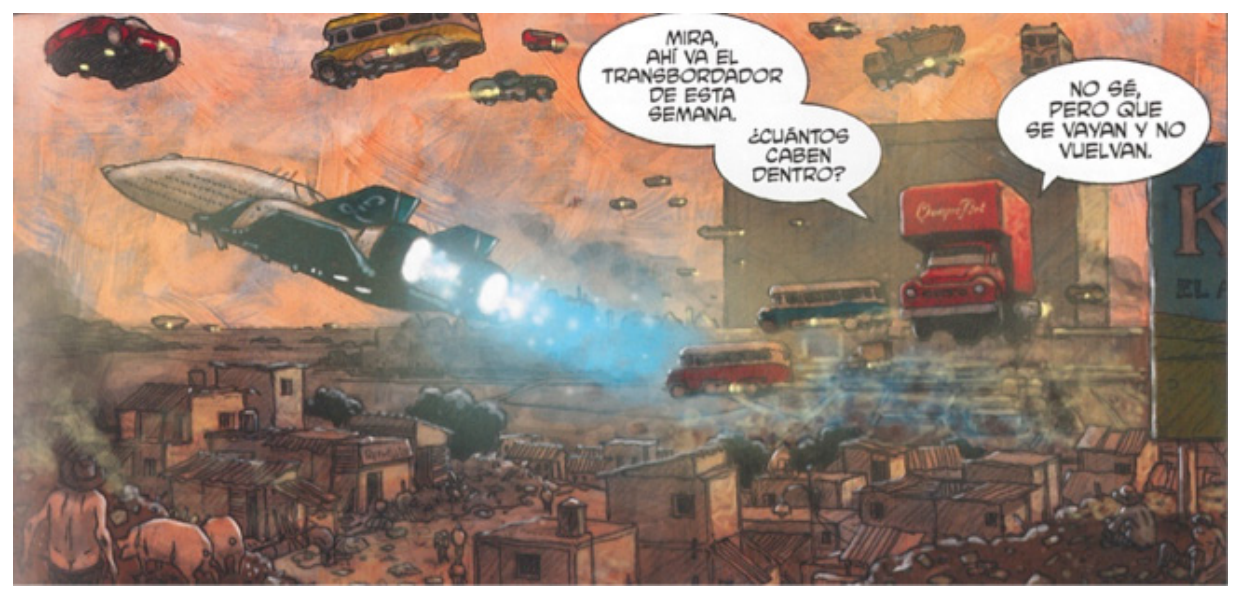

A. Planeta Extra (Diego Agrimbau and Gabriel Ippóliti, Argentina, 2009)

La historia de Planeta Extra gira en torno a un conflicto familiar desatado por una hija decidida a dejar atrás la Tierra para buscar una vida mejor en Luna Europa (el nuevo planeta) mientras que a su padre, a quien no le interesa el avance social y material, le horroriza la idea de la división de la unidad familiar. Como explica Agrimbau, esta historia del intento desesperado de fuga, y de la lucha por conseguir 


\section{Adiós a las armas}

Despatriarcar América desde la cultura

el dinero y los permisos necesarios, está basada en las migraciones hacia Europa que produjo la crisis argentina del 2001 (Abella).

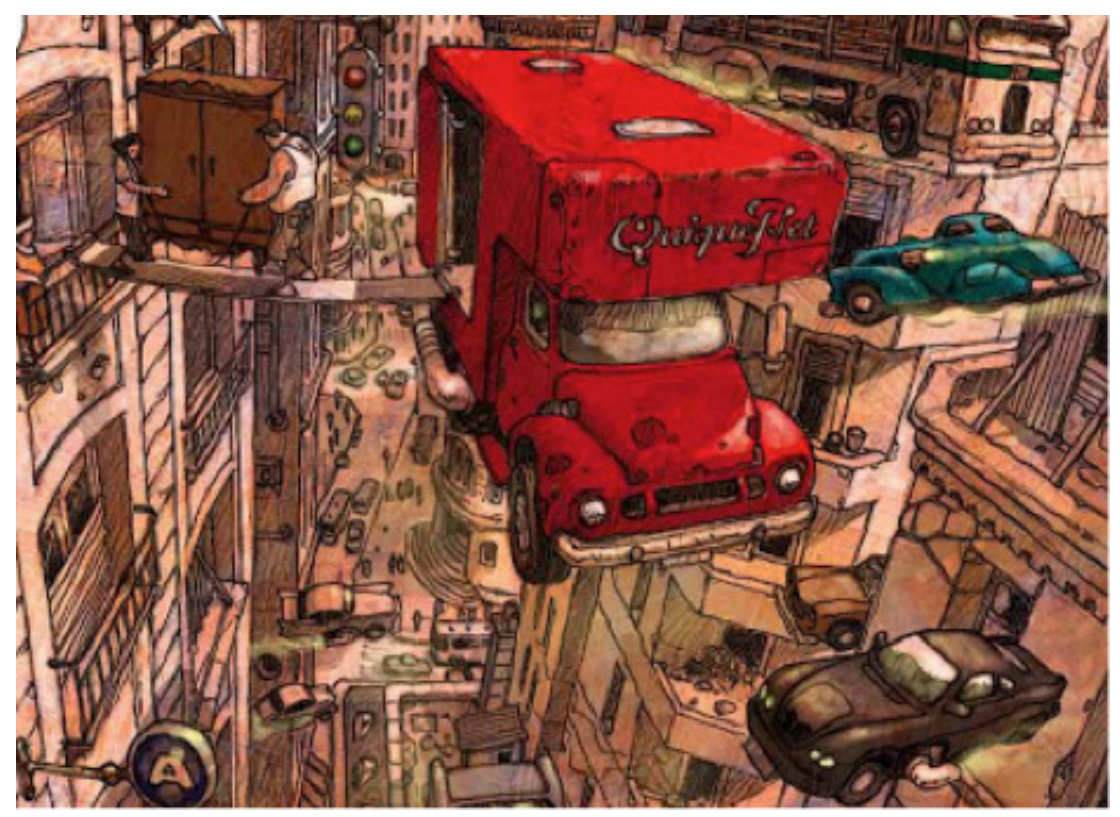

B. Planeta Extra (Diego Agrimbau and Gabriel Ippóliti, Argentina, 2009)

El texto entabla un diálogo consciente con el sainete criollo, un género que tuvo gran éxito comercial en Argentina a fines del siglo XIX y principios del XX (Valenzuela). Estas pequeñas obras de teatro, que creaban personajes típicamente idiosincrásicos dentro de un marco costumbrista, echaban una mirada tragicómica o satírica sobre la vida cotidiana en Buenos Aires durante la ola de inmigración del fin de siglo. Muchas veces enfocaban los efectos de la urbanización rápida y las tensiones entre tradición y modernidad, valores familiares conservadores e individualismo liberal. De hecho, Planeta Extra se nutre constantemente de formas y técnicas teatrales al poner el énfasis sobre la caracterización, al crear una continuidad inusual de acción, y al eliminar casi por completo las leyendas típicas de las historietas, limitándose de esta manera a contar la historia a través de gestos y globos de diálogo. La página final hasta se parece a una ovación final de teatro, al dibujar a los personajes como si estuvieran a punto de saludar ante el público (C).

Los sainetes originales, como señala Oscar Pellettieri en El sainete y el grotesco criollo, eran obras notablemente machistas y misóginas que presentaban de manera afectuosa a los maridos que golpeaban a sus mujeres inconstantes e infieles. En cambio, Planeta Extra representa al padre de familia como un inútil encantador y demasiado sentimental. Su preocupación por retener a la familia alrededor suyo lo conduce a cometer una serie de torpezas que terminan por llevar a la familia a la bancarrota. Cuando los echan de la casa, su respuesta es emborracharse. 


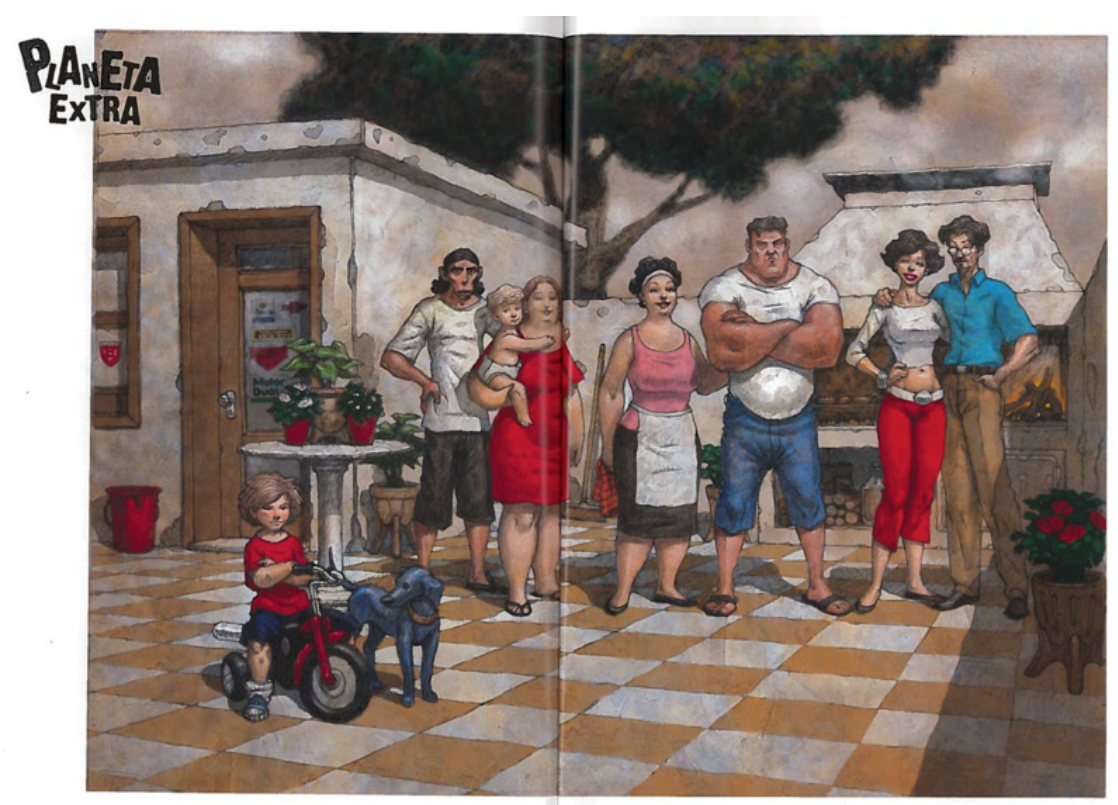

C. Planeta Extra (Diego Agrimbau and Gabriel Ippóliti, Argentina, 2009)

Parece haber dos modelos de ser macho en este mundo futurista (D). El primero está representado por el protagonista y su cuñado, que están preparados para cualquier tipo de trabajo manual, tienen pocas expectativas en la vida y tampoco tienen ambiciones en cuanto a ella, no tienen buen ojo para los negocios y se aferran a la familia nuclear tradicional. El otro modelo es ejemplificado por Pilo Artusi, el abogado poco confiable que engaña a su mujer, tiene los ojos puestos en el avance social, es especialista en llenarse los bolsillos con las ganancias de negocios sospechosos y no duda en chanteajar a la gente de vez en cuando si eso lo ayuda a salir adelante. Lo que queda claro es que los valores del hombre de familia tradicional son incompatibles con los valores del progreso capitalista. Están anclados, en cambio, en lo nacional y lo popular, ambos amenazados por la modernización global.

Podríamos entender la afinidad de Planeta Extra con el teatro criollo como parte de una aproximación más amplia al pensamiento popular examinado en la obra del antropólogo y filósofo argentino Rodolfo Kusch. Planeta Extra resalta el contraste entre ser alguien y estar nomás que para Kusch divide el pensamiento occidental y el pensamiento indígena latinoamericano, varios aspectos que también estaban presentes en el pensamiento popular de la clase obrera y la clase media baja en Buenos Aires. Ser alguien está vinculado con la idea occidental y capitalista de tener éxito y tener influencia sobre el mundo de alguien, mientras que estar nomás es la negación de ese pensamiento y el deseo simplemente de existir en un lugar, sin luchar por imponerse sobre el mundo o participar en la empresa colonialista-capitalista del Occidente. Para Kusch, "El mercader y el ser se hallan íntimamente ligados" 


\section{Adiós a las armas}

Despatriarcar América desde la cultura

(Kusch 109), porque "ser" en este sentido significa entrar en el mercado capitalista. Esta división entre el ser y el estar se dramatizan en el conflicto central de Planeta Extra. Brenda, la hija, y su novio Pilo se desesperan por "irse para arriba", de manera literal en este caso, en una nave espacial a otro planeta donde esperan disfrutar de una situación financiera mejor y más comodidades materiales. Por otro lado, al padre y al tío de ella no les interesa el avance social o económico: prefieren subsistir en los márgenes de un imperio humano cada vez más extendido. De esta manera, Planeta Extra narra la desconexión de los sectores populares de la empresa colonial-capitalista.

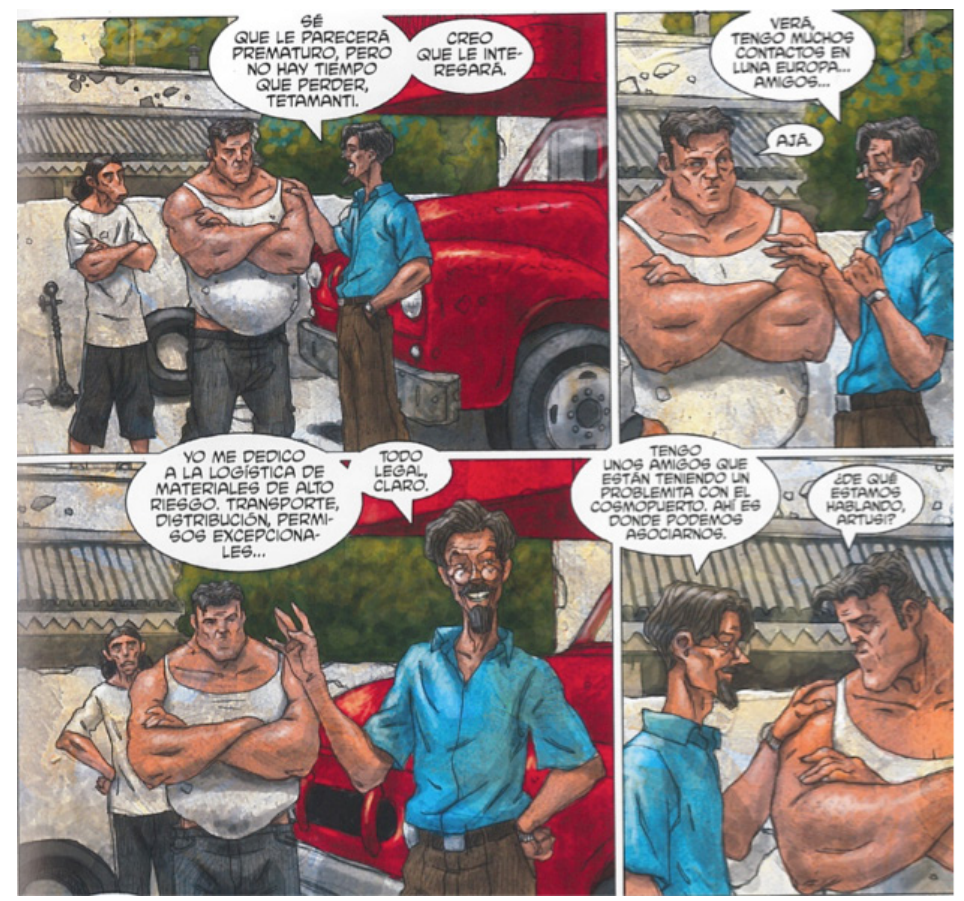

D. Planeta Extra (Diego Agrimbau and Gabriel Ippóliti, Argentina, 2009)

Como explica Kusch, el ser se asocia con valores de "poseer" y "dominar"; en las palabras de Walter Mignolo, estar significa, en cambio:

Una negación de los proyectos imperialistas y colonialistas de la modernidad para transformar el mundo en "ser alguien" ser próspero, desarrollado, civilizado como la única manera de concebir la vida y vivir la vida. La idea de "éxito" de "progreso y desarrollo", son todas construcciones ideológicas formadas por sujetos para quienes la vida se guía por la voluntad de poder y control (xxxi). ${ }^{1}$

1 "a negation of imperial and colonial designs of modernity to transform the world into 'being some
one' being successful, being developed, being civilized as the only way to conceive life and to live life. 
En el fondo, se trata aquí de distintas concepciones de la agencia humana con respecto al mundo. Planeta Extra, como varias de las obras de Agrimbau, es poshumanista en el sentido en que desmantela algunas de las suposiciones y aspiraciones que respaldan las narrativas humanistas de la civilización y la modernidad, sobre todo las que tienen que ver con la dominación humana de la naturaleza. Pero al recurrir a la tradición, al pensamiento y al arte popular como antídotos, termina reafirmando la centralidad de la agencia humana, así como los valores de libertad y realización individual, más algunas nociones de derechos y dignidades relacionadas al humanismo. Los personajes masculinos son los que más claramente encarnan el conflicto entre lo viejo y lo nuevo, lo nacional y lo popular por un lado y lo global y lo tecnológicamente avanzado por el otro, y que tienen que negociar el camino en un mundo para el cual no siempre se encuentran bien equipados. Pero son estos personajes los que también conllevan la crítica que hace Agrimbau a la modernidad occidental como una práctica de la dominación.

En Angela Della Morte de Salvador Sanz, encontramos un acercamiento muy distinto al tema del poshumanismo. La obra combina la ciencia ficción y el horror con el fin de narrar sueños delirantes de la perfección humana que solo conducen a la monstruosidad y la violencia. Expone el lado oscuro de la versión posbiológica del poshumanismo, quizás más conocida como el transhumanismo, y difundida por científicos especulativos como Hans Moravec, Raymond Kurzweil y Frank Tipler. Los textos de Sanz construyen una crítica de un poshumanismo que deja atrás el cuerpo humano, y de una visión descorporizada de la cibercultura. El género juega un rol importante en el énfasis que pone sobre la corporización y la materialidad.

La predicción de los transhumanistas acerca de la posibilidad futura de liberar la conciencia humana del cuerpo que la alberga está basada en un dualismo cartesiano entre mente y cuerpo, en que la actividad mental predomina por sobre la experiencia encarnada. Esta visión entra en conflicto directo con las versiones más críticas del poshumanismo desarrolladas por Rosi Braidotti, N. Katherine Hayles, Karen Barad, Neil Badmington y Bruce Clarke. Estos teóricos, en cambio, se asocian más a "la tesis de la mente extendida" al aproximarse al cuerpo como parte indivisible de nuestra percepción y a la mente como producto de múltiples interacciones con nuestro entorno.

Angela Della Morte nos ofrece un abordaje crítico al sueño transhumanista de la conciencia desmaterializada. Para Sanz, este camino a la supuesta perfección humana abre la puerta a un sinfín de maldades. De epígrafe, para el primer volumen, pone una cita muy apropiada de Descartes: "Es evidente que yo, mi alma, por la cual soy lo que soy, es completa y verdaderamente distinta de mi cuerpo, y puede ser o existir sin él” (23). En el mundo creado por Sanz, una conciencia humana

The idea of 'success' of 'progress and development' are all ideological constructs by subjects for whom life is guided by the will to power and control". 


\section{Adiós a las armas}

Despatriarcar América desde la cultura

sobrevive la muerte del cuerpo por 35 minutos. Tiene que buscarse otro cuerpo donde alojarse, y si no lo encuentra, deja de existir. El alma, una vez liberada del cuerpo, puede volar por el aire "como una nube desprovista de materia" hasta que encuentre "un desalmado" un cuerpo sin alma que yace abandonado como un traje, esperando que otra alma le recoja (E). Hasta ahora, todo muy cartesiano.

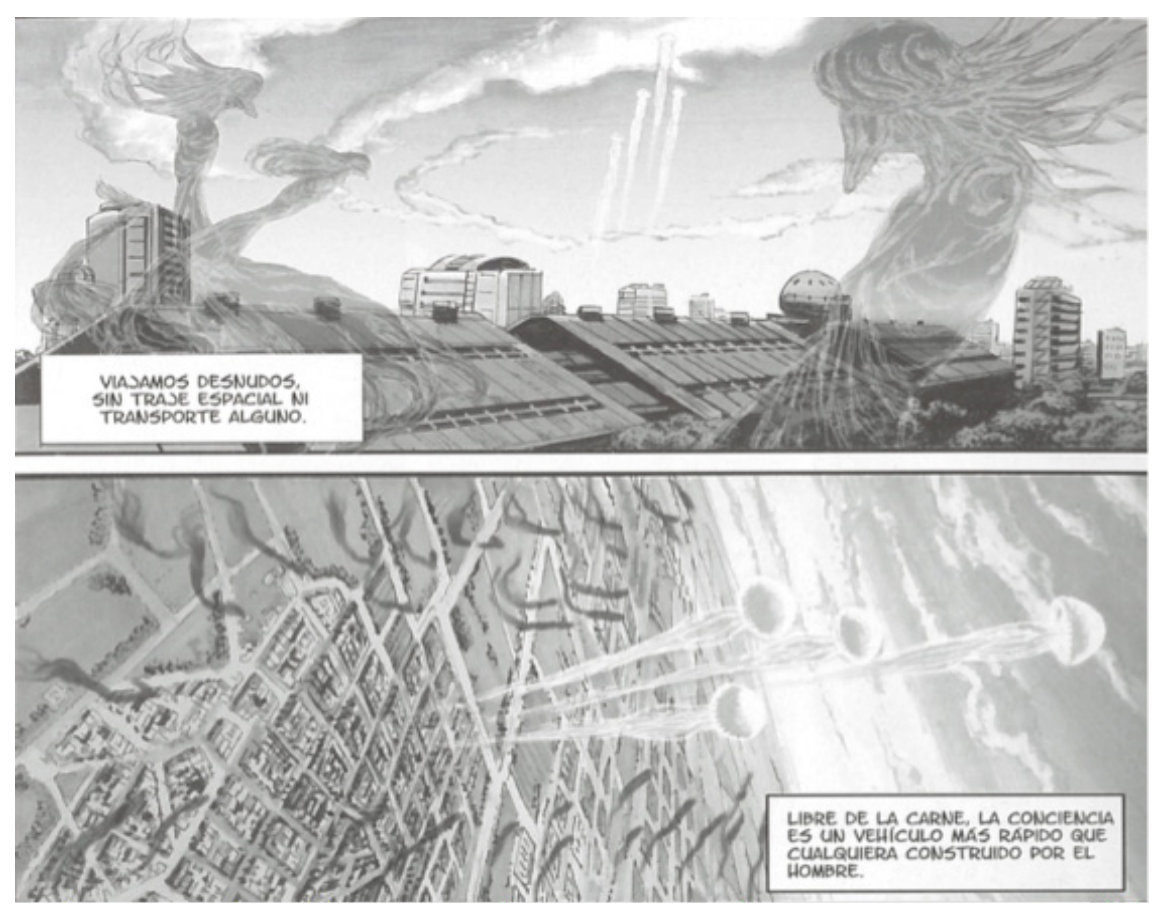

E. Salvador Sanz, Angela Della Morte vol. 2 (Argentina, 2011)

Pero la mayor parte de la narrativa de Angela Della Morte se empeña en desarmar esas premisas y en reforzar la importancia de la corporización material en la experiencia humana (y animal). Angela y los demás personajes nunca logran adaptarse a su forma de vida nómada de trueque de cuerpos, y lloran la pérdida de sus cuerpos originales. Experimentan una inadaptación constante que se multiplica si el nuevo cuerpo es de otro género. Hasta las experiencias más cotidianas, como optar por un baño público en vez de otro, conducen a una sensación de estar desfasado o desconectado de su propio cuerpo. Si Sanz parece contemplar la posibilidad de una conciencia posbiológica, al mismo tiempo señala hasta qué punto la identidad humana está intrínsecamente atada a la experiencia corpórea y no puede separarse de ella. Al final, el escenario poshumano de Angela Della Morte solo nos recuerda, de modo conmovedor, que -en las palabras de Hayles- "el ser humano es antes de todo un ser corporal" $(283) .^{2}$

2 "human being is first of all embodied being". 

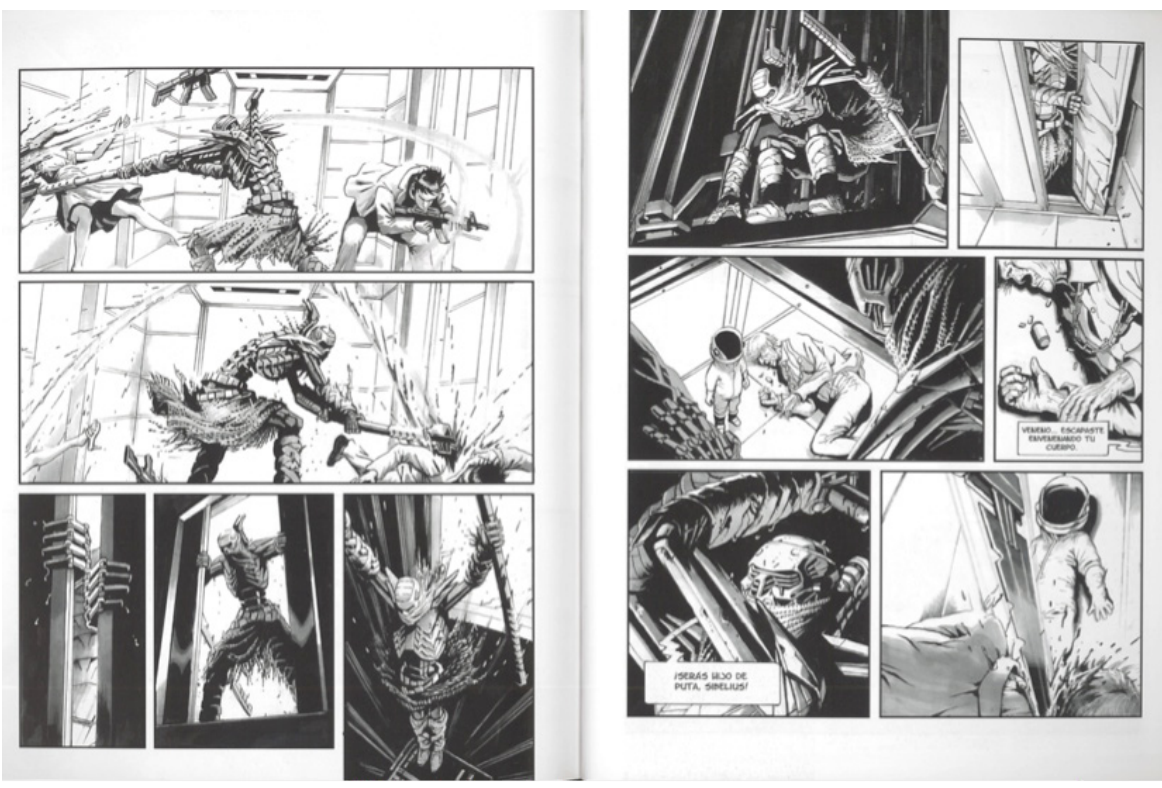

F. Angela Della Morte, vol. 2 (Salvador Sanz, Argentina, 2011)

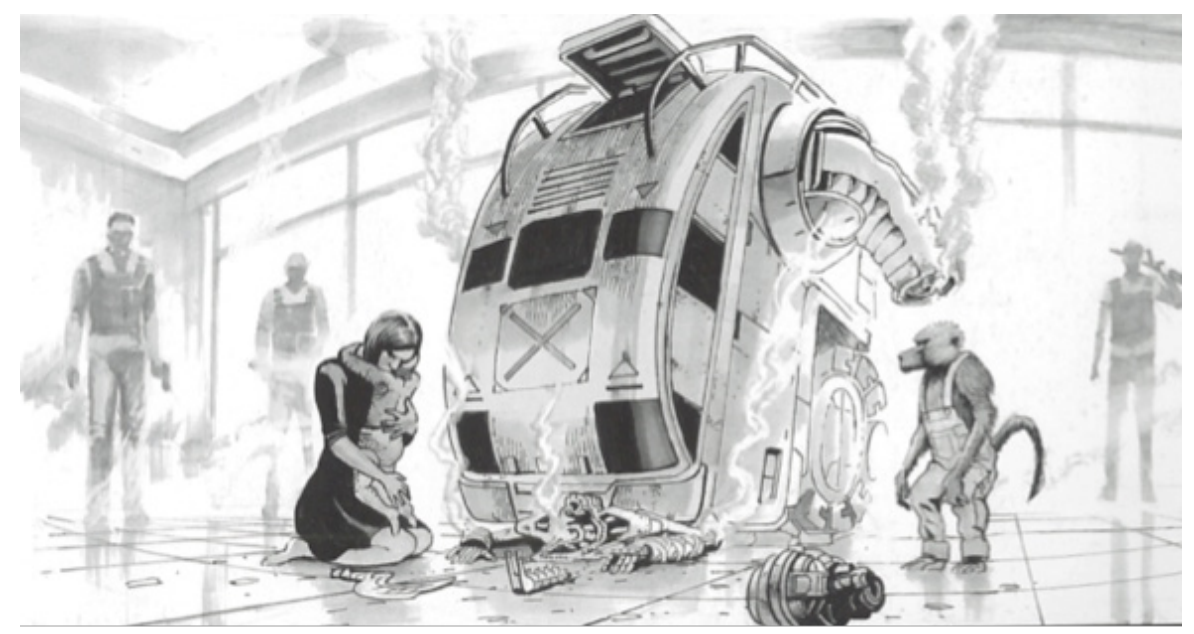

G. Angela Della Morte, vol. 2 (Salvador Sanz, Argentina, 2011)

Las viñetas finamente dibujadas de Sanz, en que la acción violenta predomina por sobre el diálogo y el pensamiento, enfatizan la vulnerabilidad del cuerpo humano en un mundo de máquinas acorazadas de acero (F). Angela Della Morte termina con una imagen de Angela que abraza a su hijo, sabiendo perfectamente que este acto bien podría conducirla a la muerte, porque el niño es portador de una forma contagiosa del mal $(G)$. Pero es incapaz de no responder a la aflicción 


\section{Adiós a las armas}

Despatriarcar América desde la cultura

del bebé, que clama por los brazos de su mamá. La historia termina, entonces, con una reafirmación de la importancia del tacto y de lo corpóreo, y con un reconocimiento de las raíces biológicas de la experiencia humana. Podríamos ver la reintroducción de lo biológico como un acto retrógrado en el contexto en que el género ya se entiende como una construcción social. Pero aquí expone los peligros de una versión del poshumanismo que intenta dejar atrás la biología y, al mismo tiempo, se olvida de la ética y de la misericordia. Logra además reinsertar las prácticas del cuerpo en las teorías sociales y de género de las cuales, como sostiene Connell, muchas veces son extraídas, lo que hace más fácil tratarlas como objetos discursivos o simbólicos.

En dos ejemplos excelentes de la novela gráfica contemporánea en Chile -Policía del Karma y E-Dem: La conspiración de la vida eterna. Desarraigo- encontramos una profundización en temas de género, y sobre todo en la masculinidad, como parte de una investigación más general de la corporización en una época poshumana. Estos textos llaman la atención sobre cómo los cuerpos se convierten en escenarios tanto de la explotación como de un nuevo giro ético.

Policía del Karma, de Jorge Baradit y Martín Cáceres, combina elementos de las variantes ciberpunk y steampunk de la ciencia ficción. Sus tecnologías recuerdan una época industrial y evocan la maquinaria de una fábrica de la era soviética. No hay nada digital en Policía del Karma: todo es dolorosamente corpóreo, y los enganches humano-máquina tantas veces imaginados en ficciones futuristas están retratados aquí de manera grotescamente literal, con cables y enchufes metidos a presión en cada orificio. Incluso los modos virtuales o supernaturales de conexión transindividual se vuelven totalmente materiales; se miden y se controlan las esencias y los flujos espirituales como si fueran sustancias químicas o cargas eléctricas. Cada sector de la sociedad en Policía del Karma juega un rol único en exprimir y procesar distintas fuentes de energía e información. Los "nepaleses", por ejemplo, se mantienen en un estado permanente de coma y funcionan como "módems humanos", "convirtiendo efluvios astrales en información digital descargable".

Policía del Karma desacredita por completo el mito de una existencia virtual y descorporizada en el ciberespacio donde los humanos-cyborg gozarían de poderes aumentados. La tecnología de época industrial representada aquí resalta la vulnerabilidad del cuerpo humano al dolor: cada contacto entre cuerpo y máquina es insoportable. No se trata de una representación típica del ciberespacio en que la robótica reemplaza la labor humana y la existencia virtual parece prescindir de las necesidades y limitaciones biológicas. Aquí, los humanos están enredados de manera física en el sistema, en que actúan como dientes, módems o conductos. La intrusión brutal de las máquinas en los cuerpos humanos se ven claramente en los dibujos de orificios violados y con pieles estiradas a través de ganchos de carnicero (H). El uso de un efecto de aguada hace posible una complejidad de dibujo raras veces vista en las historietas, al evitar la simplificación de los objetos y el refuerzo 
de las líneas divisorias entre ellos producidos por un uso más convencional de color en bloque. Las aguadas, por lo general de color sepia o de un azul frío y metálico, intensifican la austeridad de este mundo. También dejan libre al dibujante para que pueda crear un trazado muy fino de líneas. Esta técnica hace resaltar todos los cables, las conexiones, los enchufes y las tomas de corriente en este mundo steampunk de hiperconexión (I).

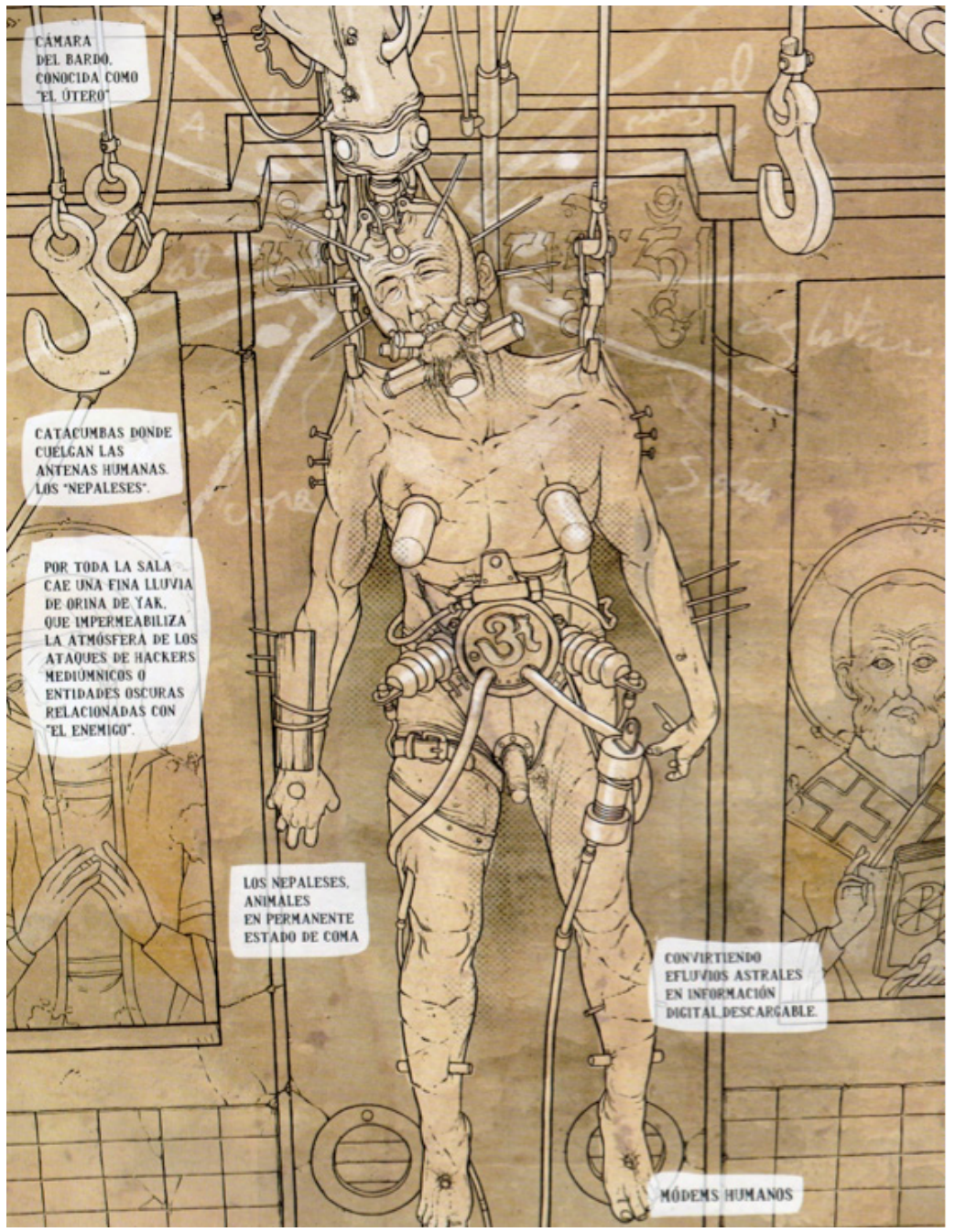

H. Policía del Karma (Jorge Baradit y Martín Cáceres, Chile, 2011)

Las múltiples excitaciones, penetraciones y acoplamientos de Policía del Karma le dan una marcada carga sexual. Como en muchos textos ciberpunk, los rasgos sexuales y de género son fuertemente acentuados. La representación de género en el ciberpunk ha sido un tema de debate, y varios críticos han arremetido contra su vi- 


\section{Adiós a las armas}

Despatriarcar América desde la cultura

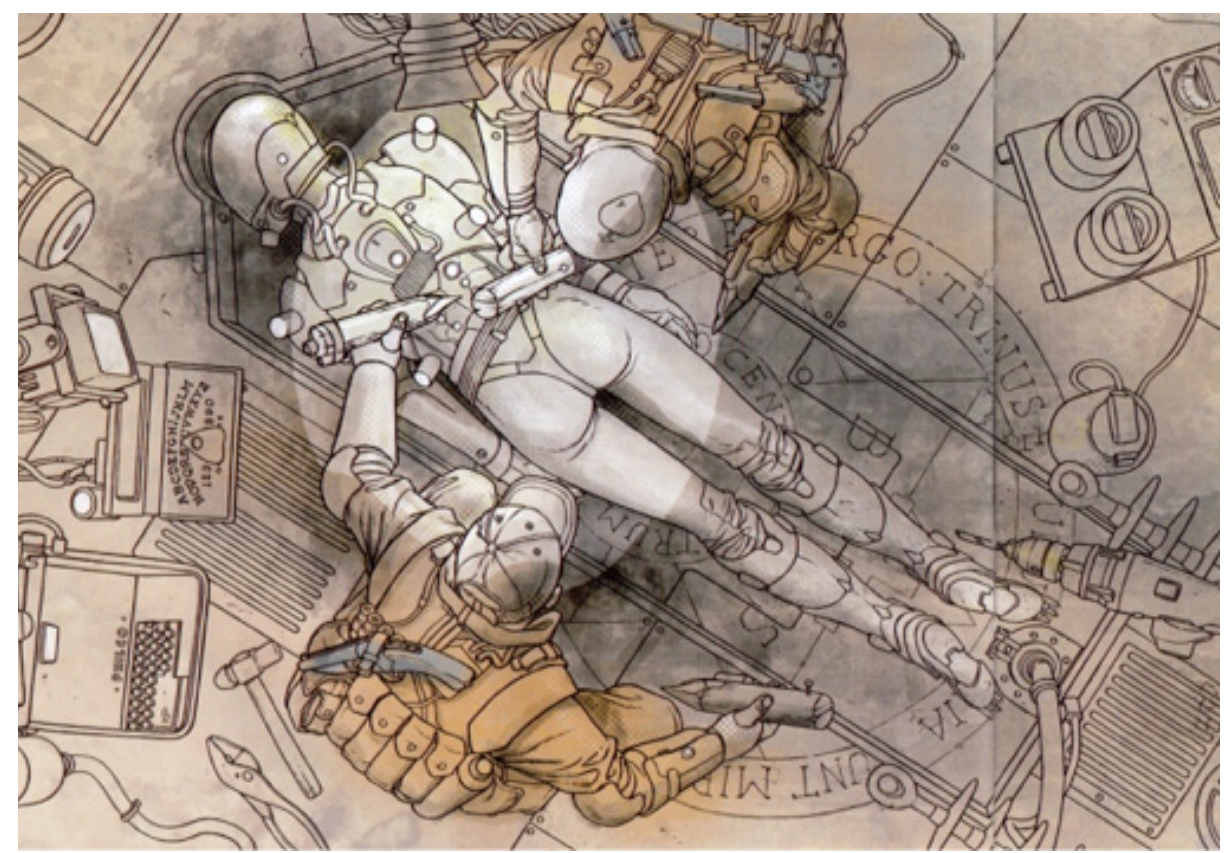

I. Policía del Karma (Jorge Baradit y Martín Cáceres, Chile, 2011)

sión masculina y su perpetuación de estereotipos de género. Para Andrew Ross, el ciberpunk es "un armazón barroca hecho de fantasías de adolescentes masculinos" (145) ${ }^{3}$ Nicola Nixon sugiere que el mundo alternativo construido en Neuromancer de William Gibson "no solo permite la reafirmación del dominio varonil sino también una celebración virtual de una especie de masculinidad primitiva" (204). ${ }^{4}$ Para otros críticos, el género es tratado de una manera mucho más ambigua en el ciberpunk: parece al mismo tiempo reforzar y subvertir los estereotipos (Cavallaro). En su análisis del cine ciberpunk, Samantha Holland señala la raíz del problema: "los cuerpos musculados y hipermasculinos de los yyborgs varones pueden leerse o como reafirmaciones directas de la masculinidad hegemónica, o como histéricas compensaciones en exceso por una masculinidad en crisis" (166). ${ }^{5}$

La representación del género en Policía del Karma es aún más ambigua. Si todas las relaciones de poder están claramente basadas en la diferencia de género, en algunas de ellas dominan los varones y en otras las mujeres. Los acosadores soldados de la PDK están bajo el mando de seres femeninos llamados "las Muertas"; de manera parecida, son las Orugas, también femeninas, que controlan los Nepaleses

\footnotetext{
3 "a baroque edifice of adolescent male fantasies".

4 "allows not only a reassertion of male mastery but a virtual celebration of a kind of primal masculinity". 5 "the pumped-up hyper-masculine bodies of the male cyborgs can be read either as straight reassertions of hegemonic masculinity, or as hysterical over-compensations for a masculinity in crisis".
} 
masculinos. Presenciamos una igualdad monstruosa de género en el rapto sistemático del tercer hijo - masculino o femenino- de cada familia, que está puesto al servicio de la sociedad: o desmembrado para formar parte de una máquina industrial, o esclavizado para convertirse en juguete sexual para la élite, o reclutado como soldado de la PDK.

Los críticos que han enfocado el tratamiento del género en el ciberpunk muchas veces se han centrado en la representación del hacker varón que se enchufa al ciberespacio, representado como femenino, que se convierte en un espacio de aventura y autosuperación que espera ser dominado por el varón. La dinámica de género en Policía del Karma es mucho más ambigua: tanto los cuerpos femeninos como los masculinos son invadidos, y no impera un imaginario heterosexual en cuanto a la operación del ciberespacio. De hecho, los soldados de la PDK son más invadidos que invasores, enchufados a un "hub con mil tentáculos" insertados en el ano. De esta manera, "La muerta" el ser comandante, los forjará en una sola conciencia durante las operaciones de la PDK, hasta el punto de que "Cuando ataquemos seremos uno. Podrán sentir a cada uno desde su interior". El mundo de Policía del Karma se caracteriza por penetraciones múltiples y mutuas que nos alejan de cualquier representación heteronormativa del ciberespacio.

Rige en el texto una hipermasculinidad generalizada, pero no está presentada como un ideal. Listos y preparados para aniquilar el enemigo, los soldados de la PDK tienen todo el equipamiento de la masculinidad, desde las bazucas hasta las herramientas variadas que llenan cada bolsillo de sus uniformes (J). Se muestran lascivos y sexistas frente a Mariana, la nueva recluta: la llaman por varios nombres groseros, aprovechan para manosearla siempre y cuando se presente la oportunidad, suponen que pondrá en riesgo la operación con su debilidad de mujer. Incluso amenazan con violarla si no toma un sedante.

La masculinidad también se vincula, en sintonía con otros lugares comunes, al tamaño de la erección y a la habilidad para la caza. Tenzing, uno de los nepaleses que está conectado al ciberespacio, se excita a causa de la caza de la PDK y logra revelar la ubicación del hombre perseguido a través de la energía concentrada en su poderosa erección. Sin embargo, esta produce una sobrecarga sensorial que amenaza con provocar un cortocircuito. Tenzing pierde el control y simplemente se rinde ante el placer, y por eso tienen que desconectarlo del sistema que está poniendo en peligro; a su vez, este acto lo llevará a su muerte. De esta manera, la representación del género y de la sexualidad en Policía del Karma muchas veces actúa como una metáfora para los peligros de la hiperconectividad en un mundo cyborg. La hiperconectividad puede aumentar el placer, pero al mismo tiempo produce una sobrecarga que no puede controlarse y que termina con la muerte. Conectarse al ciberespacio para los soldados de la PDK también pone en funcionamiento un proceso que terminará en la muerte de ellos. Se inserta un virus que les permite 


\section{Adiós a las armas}

Despatriarcar América desde la cultura

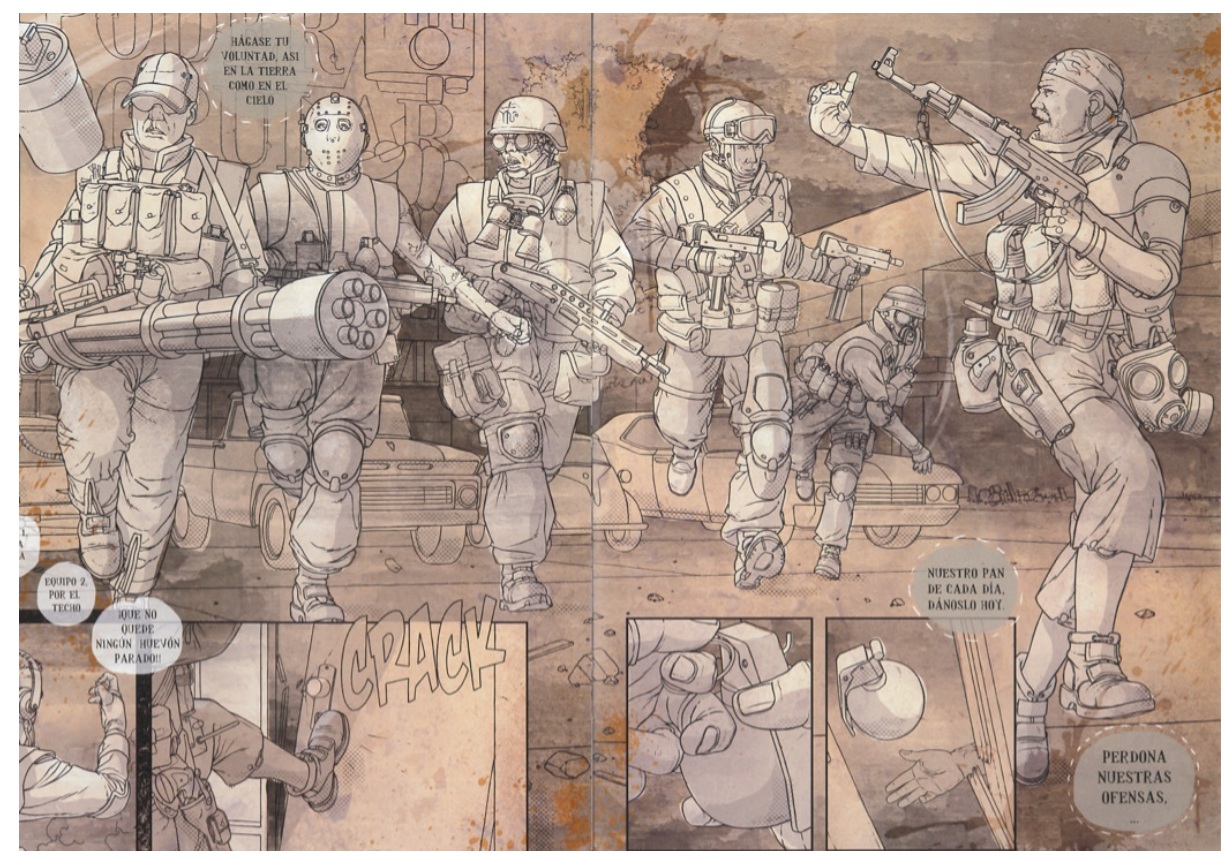

J. Policía del Karma (Jorge Baradit y Martín Cáceres, Chile, 2011)

participar, de manera temporaria, en una consciencia colectiva, pero que al final los matará.

En general, la representación del género en Policía del Karma podría verse como una aproximación a una crisis de la masculinidad en un mundo hiperconectado. El militarismo fanático de los soldados aparece totalmente fuera de lugar en un mundo que exige juicios éticos mucho más sutiles. La hipermasculinidad también parece ser una máscara que esconde una sensación de falta y de vulnerabilidad: los soldados varones creen que al final no están a la par con sus colegas femeninas. El narrador (que en este momento se asocia con la voz de un soldado de la PDK), nos cuenta que "la Muerta" es la "verdadera" PDK y que "nosotros somos basura al lado de su resplandeciente alma". Las Muertas siempre son mujeres, nos dice, y tienen poderes especiales que les permite procesar la información que reciben de los nepaleses y participar en una consciencia colectiva únicamente para ellas. Los soldados temen que las mujeres sean más capaces de adaptarse a un mundo de conectividad virtual.

Policía del Karma se llena de cuerpos que son raptados, violados, desmembrados, sacrificados, esclavizados o que se encuentran en descomposición como resultado de su acoplamiento a los sistemas social, laboral y de información. Al final, el texto nos conduce lejos de cualquier visión social, cultural o ideológica del género y de la sexualidad. Nuestros distintos orificios no tienen ninguna significación más allá 
de su empleo como enchufes y tubos que nos conectan de manera específica a un sistema de comunicación. Lo que prevalece es una sensación profunda de vulnerabilidad física en un mundo cada vez más conectado: si estos enchufes múltiples aumentan nuestros conocimientos y nuestra capacidad para comunicarnos, y hasta permiten la operación de una consciencia transindividualista, también son puntos de extrema vulnerabilidad. La violencia extendida y muchas veces arbitraria del mundo de Policía del Karma, junto con este énfasis sobre la materialidad de los cuerpos, nos conduce a entender esta vulnerabilidad como el punto de partida para una visión ética, tal como la presenta Judith Butler en Vida precaria:

El cuerpo supone mortalidad, vulnerabilidad, praxis (agency): la piel y la carne nos exponen a la mirada de otros, pero también al contacto y a la violencia []. Constituido en la esfera pública como un fenómeno social, mi cuerpo es y no es mío. Entregado desde el comienzo al mundo de los otros, el cuerpo lleva sus huellas, está formado en el crisol de la vida social (26). ${ }^{6}$

Sería posible leer Policía del Karma como un ejemplo hiperbólico del tipo de conexiones que describe Butler, que nos dejan "expuestos a otros y susceptibles de violencia a causa de esta exposición" (46). ${ }^{7}$ Como muchos textos de ciencia ficción, Policía del Karma reinscribe en lo material y lo literal lo que se había convertido en una metáfora de un elemento de la vida especial: en este caso, la conectividad. Acá las conexiones entre los cuerpos humanos y entre ellos y las máquinas se vuelven materiales, de una manera que deja al descubierto nuestra vulnerabilidad cada vez mayor en una época cibernética. Es a partir de este reconocimiento, dice Butler, que podemos encontrar "las bases para la comunidad" $(45)^{8}$ en un violento mundo contemporáneo.

Este llamado por una nueva ética se profundiza en E-Dem: La conspiración de la vida eterna. Desarraigo de Cristián Montes Lynch, otro aporte espectacular de Chile a la novela gráfica contemporánea. El tema del género juega un rol importante en la investigación que lleva a cabo acerca de los vínculos siniestros entre el falocentrismo, la religión, la tecnología, la violencia del estado y las políticas de exclusión. La primera parte narra el despertar de una forma masculina, mitad humana y mitad árbol, cuyo tronco queda incrustado en la tierra de la cual se ha brotado (K). El hombre elegido por la Diosa Fortuna es tirado violentamente, con mucho dolor, de la tierra para comenzar la primera etapa de su germinación. Se vuelve pareja del Ángel Fecundado, que tiene un cuerpo femenino, en una coreografía apa-

6 "The body implies mortality, vulnerability, agency: the skin and the flesh expose us to the gaze of others, but also to touch, and to violence [...]. Constituted as a social phenomenon in the public sphere, my body is and is not mine. Given over from the start to the world of others, it bears their imprint, is formed within the crucible of social life".

7 "at risk of violence by virtue of that exposure".

8 "a basis for community". 


\section{Adiós a las armas}

Despatriarcar América desde la cultura

sionada que lo condiciona para la transformación espiritual que debe emprender y para el brote de sus alas. Los dibujos, por lo general libres de leyendas o globos de diálogo, nos sumergen en la sensualidad pura de piruetas largas y exquisitas, en las que el Ángel y su nuevo aprendiz suben y giran por el aire, abrazándose el uno al otro en preciosos arabescos (L). Esta primera narrativa hace eco del mito del carro alado de Platón, en que la Razón guía el ascenso deseado del alma hacia la belleza y la sabiduría, mientras que los apetitos más primitivos del hombre lo arrastran a la tierra. En E-Dem, en cambio, es la Razón misma la que alimenta las fantasías del hombre de posesión y dominación sexual: "Surge la razón y con ella, la necesidad de explorar, conocer, entender, dominar la tierra y poseer la carne".

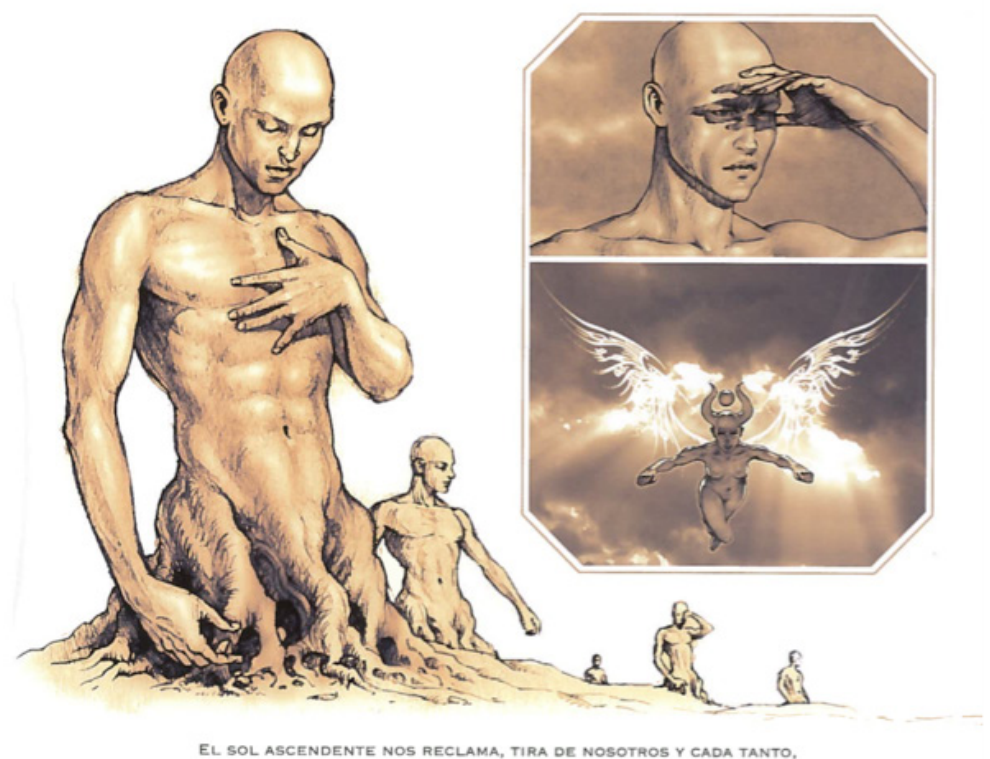

NOS ENVIA UN ANGEL FECUNDADO PARA GERMINARNOS.

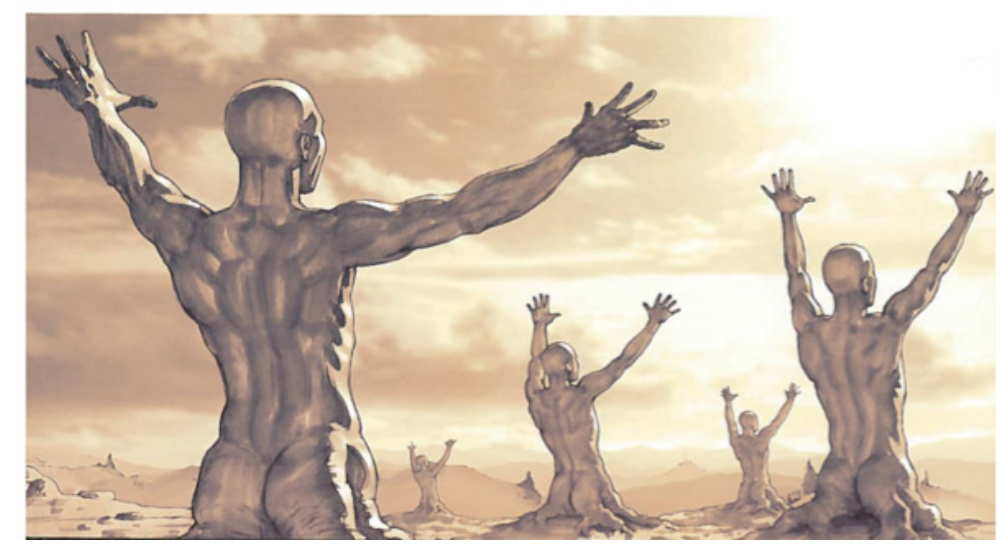

K. E-Dem: La conspiración de la vida eterna. Desarraigo (Cristián Montes Lynch, Chile, 2012) 

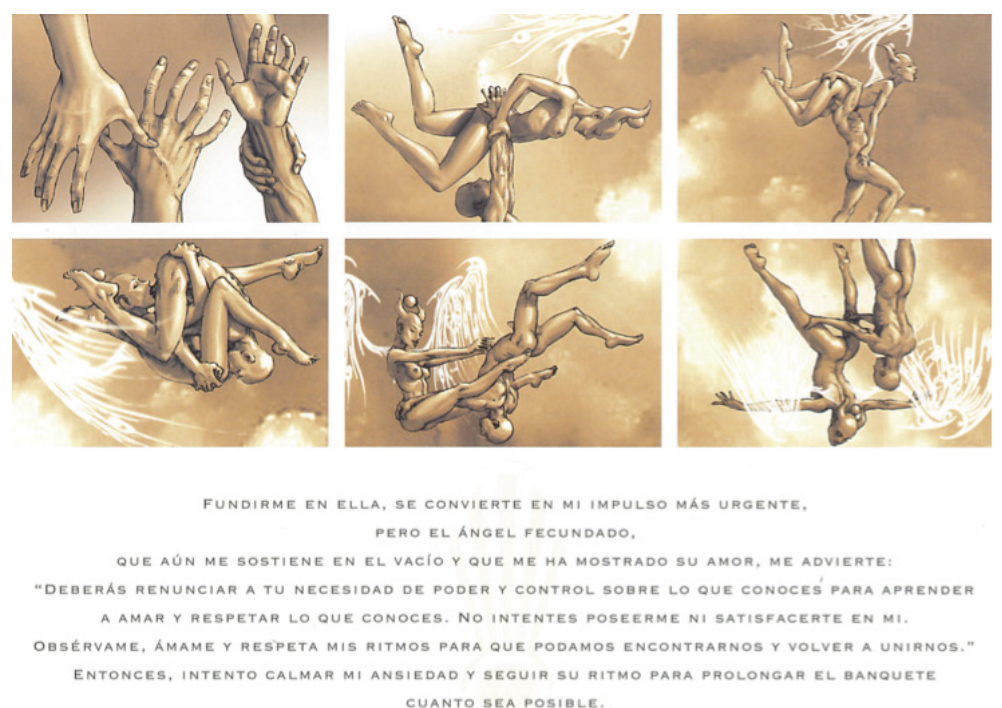

CUANTO SEA POSIBLE.
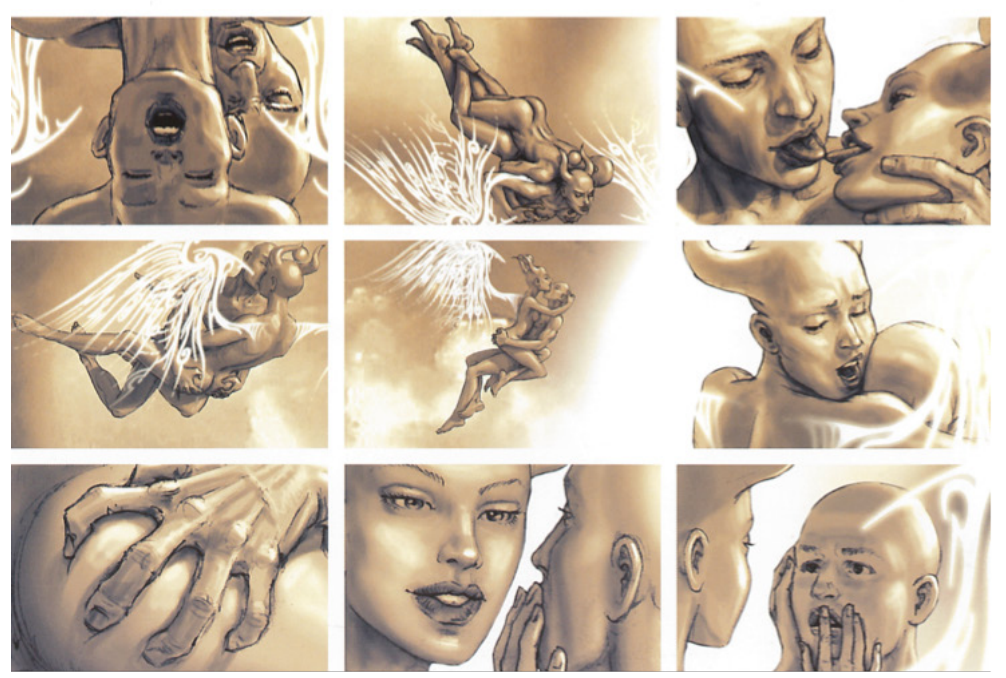

L. E-Dem: La conspiración de la vida eterna. Desarraigo (Cristián Montes Lynch, Chile, 2012)

Las otras narrativas que componen E-Dem extienden esta crítica a las distintas prácticas de la dominación. Una serie de analogías visuales une la violencia política y sexual bajo la dictadura de Pinochet con símbolos religiosos y armas futuristas. El énfasis puesto en la forma fálica de la picana (M), repetida en los adornos del Templo de la Orden de los Caballeros de la Redención y las lanzas electrificadas, traza la extensión de un dominio marcadamente masculino hasta toda dimensión de la vida social, política, tecnológica y religiosa. En cambio, cuando volvemos 


\section{Adiós a las armas}

Despatriarcar América desde la cultura

a las escenas elegantes de coreografía, en las que el hombre y el ángel femenino giran eufóricamente por el aire, estas anuncian una forma más igualitaria de unión que no está basada en el dominio. Si en las primeras secuencias del baile celestial la diferenciación sexual está fuertemente marcada, con un contraste entre el torso musculado del varón y las curvas más suaves de la mujer, en otras secuencias resulta más difícil distinguir los cuerpos: los rasgos faciales del hombre se feminizan de una manera notable.

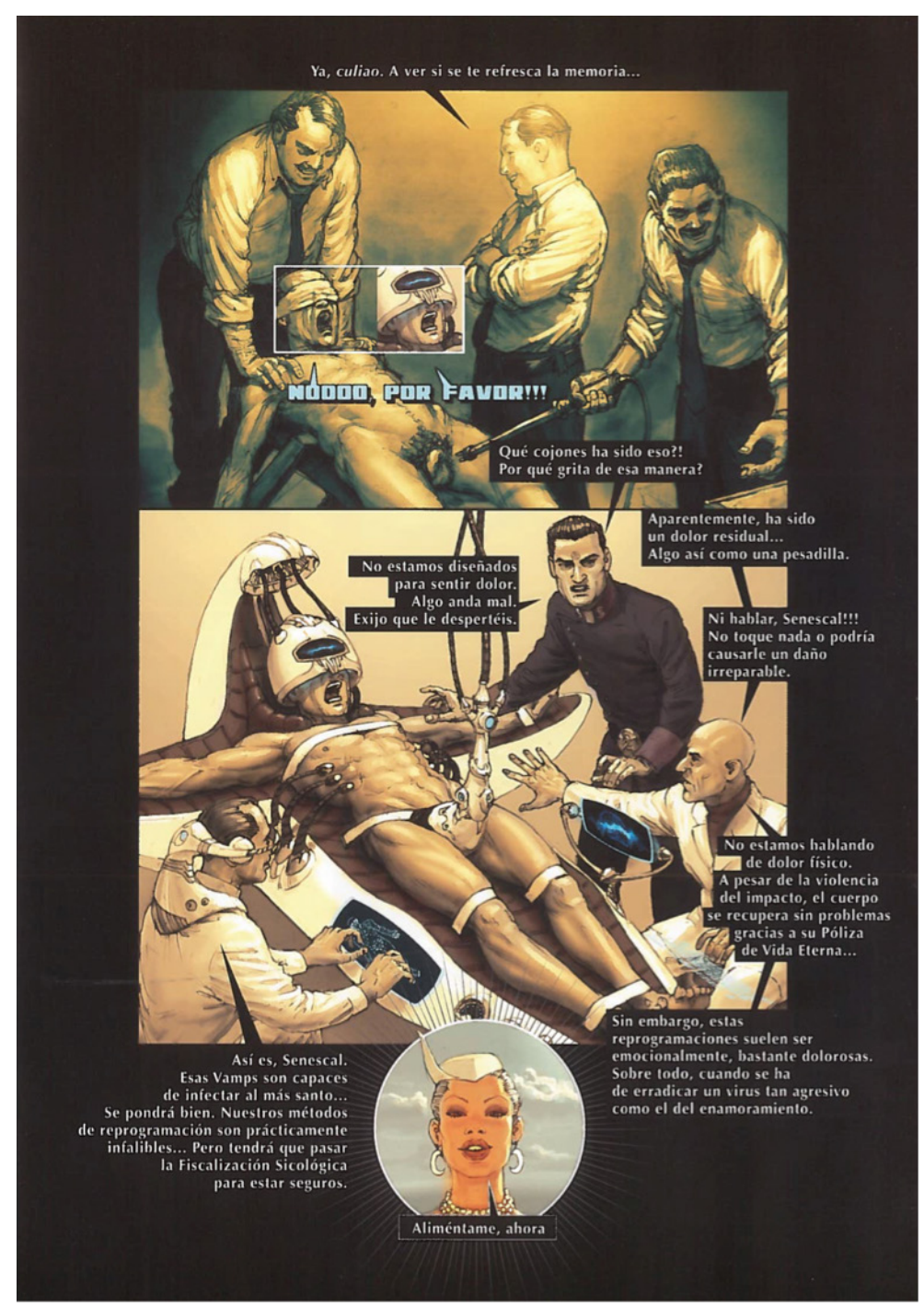

M. E-Dem: La conspiración de la vida eterna. Desarraigo (Cristián Montes Lynch, Chile, 2012) 
E-Dem exhorta a sus lectores a descubrir otra forma de orientarse hacia el mundo que no esté arraigada en conceptos de trascendencia ni de dominación. El Ángel le advierte al hombre elegido que "Deberás renunciar a tu necesidad de poder y control sobre lo que conoces para aprender a amar y respetar lo que conoces. No intentes poseerme ni satisfacerte en mí". Es la Razón la que no le permite integrarse plenamente con el universo alrededor de él, y solo el amor lo ayudará a recuperar ese vínculo perdido. El hombre descubre que es "parte de un todo infinito en el que la muerte ya no existe" y por eso deja de temer. Llega a entender que la libertad significa librarse de ideologías, religiones y un conocimiento del mundo usado como herramienta de poder y exclusión. De esta manera, Montes Lynch construye una visión poderosa y poshumanista que critica la identificación humanista de la razón con el dominio del mundo, reemplazando esta por una relación más afectiva con el mundo que no busque subyugarlo.

\section{Conclusiones}

De maneras distintas, entonces, estas novelas gráficas se nutren de representaciones estereotipadas o hiperbólicas del género, y especialmente de la masculinidad, con el fin de criticar ciertas concepciones del progreso capitalista o de la modernidad y los sueños de un futuro humano posbiológico. Enfatizan los elementos biológicos y materiales de la percepción y experiencia humana, e insisten en que el mundo poshumano será uno en que la corporización tendrá más importancia y no menos, y que esta formará la base de una nueva ética poshumanista. Como sostiene Hayles, en realidad el borramiento de lo corpóreo en el poshumanismo cibernético termina por promover los objetivos del humanismo liberal en vez de desmantelarlos: "Solo el hecho de que el cuerpo no se identifique con el ser hace posible afirmar la universalidad notoria del sujeto liberal, una afirmación que depende del borramiento de los indicadores de diferencia corpórea, incluso los de raza, sexualidad y etnicidad" (4-5). ${ }^{9} \mathrm{Al}$ recordarnos la importancia de la experiencia específica material y encarnada, que se diferencia también según el género, estos proyectos de ficción se hermanan con el de Hayles, que intenta "mostrar lo que tuvo que ser elidido, suprimido y olvidado para que la información perdiera a su forma corporal" (13). ${ }^{10}$

9 "Only because the body is not identified with the self is it possible to claim for the liberal subject its notorious universality, a claim that depends on erasing markers of bodily difference, including race, sex, and ethnicity"

10 "show what had to be elided, suppressed, and forgotten to make information lose its body". 


\section{Obras citadas}

Abella, Anna. "Una historia futurista gana el primer premio de cómic de Planeta." El Periódico de Catalunya, febrero 2009, p.8, http:/ / archivo.elperiodico.com/ed/20090206/ exit/pag_008.html.

Butler, Judith. Vida precaria. El poder del duelo y la violencia, translated by Fermín Rodríguez, Paidós, 2006.

Cavallaro, Dani. Cyberpunk and Cyberculture: Science Fiction and the Work of William Gibson. Athlone Press, 2000.

Connell, R. W. Masculinities. Second Edition, Polity, 2005.

Descartes, René. Discourse on Method and Meditations. Dover, 2003.

Hayles, N. Katherine. How We Became Posthuman: Virtual Bodies in Cybernetics, Literature, and Informatics. University of Chicago Press, 1999.

Holland, Samantha. "Descartes Goes to Hollywood: Mind, Body and Gender in Contemporary Cyborg Cinema" Cyberspace/Cyberbodies/Cyberpunk: Cultures of Technological Embodiment, edited by Mike Featherstone and Roger Burrows, Sage, 1995, pp. 157-174.

Kusch, Rodolfo. América profunda. Biblos, 1999.

Mignolo, Walter. "Introduction: Immigrant Consciousness". Indigenous and Popular Thinking in América, translated by Maria Lugones and Joshua M. Price, Duke University Press, 2010, pp. xiii-liv.

Nixon, Nicola. "Cyberpunk: Preparing the Ground for Revolution or Keeping the Boys Satisfied?" Cybersexualities: A Reader on Feminist Theory, Cyborgs, and Cyberspace, edited by Jenny Wolmark, Edinburgh University Press, 1999, pp. 191-207.

Pellettieri, Osvaldo. El sainete y el grotesco criollo: del autor al actor. Galerna, 2008.

Ross, Andrew. Strange Weather: Culture, Science, and Technology in the Age of Limits. Verso, 1991. Valenzuela, Andrés. "Es ciencia ficción llevada al grotesco de la Argentina." Página/12, febrero 2009, http://www.pagina12.com.ar/diario/suplementos/ espectaculos/2-12992-2009-02-27.html. 